\title{
2-Aminobenzoyl-CoA monooxygenase/reductase Evidence for two distinct loci catalyzing substrate monooxygenation and hydrogenation
}

\author{
Bernd LANGKAU ${ }^{1}$, Petra VOCK ${ }^{1}$, Vincent MASSEY ${ }^{2}$, Georg FUCHS ${ }^{3}$ and Sandro GHISLA ${ }^{1}$ \\ ${ }^{1}$ Fakultät Biologie der Universität Konstanz, Germany \\ 2 Department of Biological Chemistry, University of Michigan Medical School, Ann Arbor MI, USA \\ ${ }^{3}$ Abteilung Angewandte Mikrobiologie, Universität Ulm, Germany, and Mikrobiologie, Institut Biologie II, Freiburg, Germany
}

\begin{abstract}
2-Aminobenzoyl-CoA monooxygenase/reductase catalyzes both monooxygenation and hydrogenation of anthraniloyl-CoA. Its reactivity with 11 substrate analogs has been investigated. Only 2 -aminobenzoylCoA (anthraniloyl-CoA) in its normal and deuterated $\left(5-{ }^{2} \mathrm{H}\right)$ form is a full substrate, and only traces of 2hydroxybenzoyl-CoA (salicyloyl-CoA) are probably monooxygenated but not hydrogenated. The purified enzyme is a homodimer and has been resolved preparatively into three major species by anion-exchange chromatography on Mono Q. All three species have the same specific activity when reconstituted to full content of FAD, they differ, however, substantially in their mode of binding FAD. The oxidized or fully reduced enzyme forms bind tightly $0.5 \mathrm{~mol} / \mathrm{mol}$ of the substrate 2 -aminobenzoyl-CoA $\left(K_{\mathrm{d}}=1-2 \mu \mathrm{M}\right)$. The enzyme can be depleted of $\approx 50 \%$ of its FAD, which corresponds to essentially complete removal from one of the two binding sites, reflecting a large difference in the affinity for FAD. From this it is deduced that the two sites are not equivalent. Removal of FAD from one binding site leads to loss of the hydrogenation capacity of the enzyme, while monooxygenation catalysis is retained. The FAD cofactors of the two binding sites differ drastically in their reactivities towards NADH, oxygen and $N$-ethylmaleimide. Exchange of reducing equivalents between the two FAD cofactors at the respective binding sites is very slow and irrelevant compared to the rates of catalysis. It is concluded that the enzyme, which has been proposed to consist of two identical polypeptide chains [Altenschmidt, U., Bokranz, M. \& Fuchs, G. (1992) Eur. J. Biochem. 207, 715-722], contains two active centers which differ substantially in their catalytic activity. One center belongs to the class of monooxygenases, the other one to the (de)hydrogenases. This must result from substantially different interaction of the same flavin cofactors with protein functional groups and is, to our knowledge, unprecedented in flavoprotein enzymology.
\end{abstract}

Keywords. 2-Aminobenzoyl-CoA; monooxygenase; reductase; flavoprotein; kinetics.

2-Aminobenzoyl-CoA monooxygenase/reductase (ABzCoA$\mathrm{M} / \mathrm{R})$, is a recently discovered novel type of flavoprotein, which, under physiological conditions, catalyzes the two following reactions (Langkau et al., 1990):

$$
\begin{aligned}
& \mathrm{ABzCOA}+\mathrm{NADH}+ \mathrm{H}^{+}+\mathrm{O}_{2} \\
& \rightarrow \mathrm{ABzOHCOA}^{*}+\mathrm{NAD}^{+}+\mathrm{H}_{2} \mathrm{O} \\
& \mathrm{ABzOHCOA}^{*}+\mathrm{NADH}+\mathrm{H}^{+} \rightarrow \mathrm{A}(\mathrm{OH}) \mathrm{H}_{2} \mathrm{CoA}+\mathrm{NAD}^{+}
\end{aligned}
$$

where $\mathrm{ABzCoA}$ is the substrate anthraniloyl-CoA, $\mathrm{ABzOH}$ $\mathrm{CoA}^{*}$ is a postulated primary intermediate, the non-aromatic, quinoid tautomer of 2-amino-5-hydroxy-benzoyl-CoA, i.e. $5 \mathrm{H}$ 2-imino-5-hydroxy-benzoyl-CoA (cf. Scheme 1, structure II), and $\mathrm{A}(\mathrm{OH}) \mathrm{H}_{2} \mathrm{CoA}$ is 2-amino-5-oxocyclohex-1-enecarboxylCoA (cf. Scheme 1, structure IV).

Correspondence to $\mathrm{S}$. Ghisla, Fakultät für Biologie, Universität Konstanz, Postfach 5560 M644, D-78434 Konstanz, Germany

Fax: +497531882966 .

Abbreviations. $\mathrm{ABz} \mathrm{CoA}-\mathrm{M} / \mathrm{R}$, 2-aminobenzoyl-CoA monooxygenase/reductase; $\mathrm{ABzCoA}, 2$-aminobenzoyl-CoA (anthraniloyl-CoA); ABzOHCoA, 2-amino-5-hydroxybenzoyl-CoA; $\mathrm{ABzOHCoA}^{*}, 5 H-2-$ imino-5-hydroxybenzoyl- $\mathrm{CoA} ; \mathrm{A}(\mathrm{OH}) \mathrm{H}_{2} \mathrm{CoA}, 2$-amino-5-oxocyclohex1-enecarboxyl-CoA; MalNEt, $N$-ethylmaleimide.

Enzymes. 2-Aminobenzoyl-CoA monooxygenase/reductase (EC 1.14.13.40/1.3.1.-).
Reaction (1) is assumed to proceed according to the general mechanism common to flavoprotein hydroxylases (Ghisla and Massey, 1989), a class of enzymes which has been extensively studied in the last two decades. In contrast to this, reaction (2) is a hydrogenation of a novel type, similar perhaps to that encountered with acyl-CoA dehydrogenases (Ghisla and Massey, 1989). A primary goal of the present work was therefore a detailed study of these two reactions, and in particular to find out whether they are each associated with a single one of the two subunits of the dimeric enzyme, in contrast to a hypothetical case in which the subunits have identical active centers which can perform both reactions.

A peculiarity of $\mathrm{ABzCoA}-\mathrm{M} / \mathrm{R}$ is its capacity to use MalNEt as an electron acceptor, a reaction which might parallel the hydrogenation activity of the enzyme (Buder and Fuchs, 1989), and which is of practical use in that it provides the basis for a convenient assay. There is a structural and chemical similarity between MalNEt and the first intermediate (Scheme 1, structure II), which has been proposed to be formed upon oxygen insertion in ABzCoA (Langkau et al., 1990).

The approach adopted for tackling the questions outlined above involved the following experiments.

a) Exploration of the specificity of the enzyme and finding of effectors which do not participate in the monooxygenation reaction but might be useful for mechanistic studies. 
Scheme 1. Reactions catalyzed by the different forms of $\mathrm{ABzCOA}$ $\mathbf{M} / \mathbf{R}$. Fully active enzyme, containing both active sites $\mathrm{E}^{\mathrm{I}}$ and $\mathrm{E}^{\mathrm{U}}$ (native $\mathrm{ABzCoA}-\mathrm{M} / \mathrm{R}$ ) catalyzes first mono oxygenation of $\mathrm{ABzCoA}(\mathrm{I})$ to yield the proposed $\mathrm{ABzOHCoA}$ intermediate (II) at site $\mathrm{E}^{\mathrm{I}}$ and subsequently hydrogenation at site $\mathrm{E}^{\mathrm{II}}$ to yield, after two tautomerization steps, the product $\mathrm{A}(\mathrm{OH}) \mathrm{H}_{2} \mathrm{CoA}(\mathrm{IV})$. In the absence of site $\mathrm{E}^{\mathrm{II}}$, such as in the case of $50 \%$ FAD-depleted ABzCoA-M/R, hydrogenation does not occur and instead rearomatization to $\mathrm{ABzOHCoA}$ (III) takes place as indicated (R, dashed arrow). The lower part of the Scheme shows the structural analogy of species II and $N$-ethylmaleimide (MalNEt) and the reduction of the latter to $\mathrm{N}$-ethylsuccinimide (SucNEt) at site $\mathrm{E}^{\mathrm{II}}$. See text for further details concerning the nature of the different species.
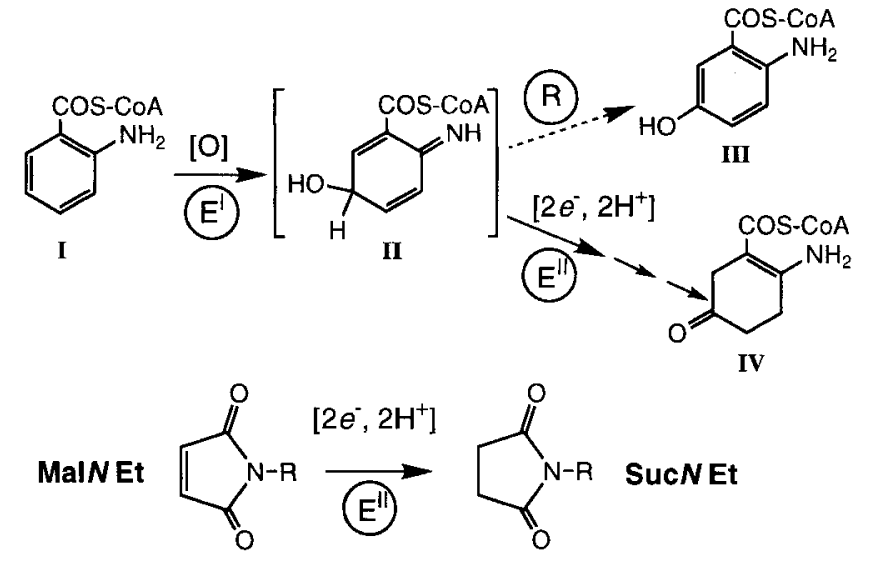

b) Study of the NADH oxidase activity, i.e. the non-productive consumption of NADH with oxygen in the absence and presence of effectors and comparison with other hydroxylases (Powlowski et al., 1987; Spector and Massey, 1972; White-Stevens and Kamin, 1970; Yamamoto et al., 1965).

c) Photoreduction and controlled reduction of the enzyme with $\mathrm{NADH}$, in the presence/absence of substrate and characterization of (half-)reduced enzyme species.

d) Reaction ('reoxidation') of half- or fully reduced enzyme with oxygen and with MalNEt.

e) Turnover and reoxidation experiments with enzyme from which FAD has been removed partially.

f) Study of the turnover with MalNEt.

A catalytic model of the NADH oxidase activity and of the turnover with MalNEt is proposed which is compatible with the experimental results. This model provides the basis for the study of the kinetic mechanism of $\mathrm{ABzCoA}-\mathrm{M} / \mathrm{R}$ with its natural substrate $\mathrm{ABzCOA}$, which will be detailed in the following paper in this journal (Langkau and Ghisla, 1995).

\section{MATERIALS AND METHODS}

Chemicals and biochemicals. Biochemicals were purchased from Boehringer (Mannheim). Benzoic acid derivatives were obtained from Sigma Chemical Co. or from Fluka. $N$-Hydroxysuccinimide was from Aldrich-Chemie. All other chemicals were obtained from Riedel-de-Häen or Merck. Argon 5.0 was purchased from SWF (Friedrichshafen) and passed through an Oxisorb catalyst from Messer Griesheim (Düsseldorf) in order to remove traces of oxygen; it was humidified prior to use. 5Bromoanthranilic acid was a gift from Dr Martin Dunkel (University of Konstanz). 4-Fluorobenzoyl-CoA, 4-aminobenzoylCoA and 4-nitrophenylacetyl-CoA were obtained from Dr Stefan Engst (University of Konstanz). Protocatechuate dioxygenase was a gift from Dr D. P. Ballou (University of Michigan).

Growth of organisms. The Pseudomonas sp. KB $740^{-}$strain was grown aerobically at $28^{\circ} \mathrm{C}$ in a mineral medium using anthranilate as sole carbon and energy source (Brown and Gibson, 1984). The amount of inducible $\mathrm{ABzCoA}-\mathrm{M} / \mathrm{R}$ was found to be strongly dependent on the conditions of growth and harvest of the cells. Although a detailed screening of all factors was not done, some specific factors have turned out to be important for obtaining a good yield of enzyme. A good supply of oxygen is mandatory, since under poor $\mathrm{O}_{2}$ supply the bacteria most probably switch to an anaerobic pathway, not involving $\mathrm{ABzCoA}$ M/R (Lochmeyer et al., 1992). Furthermore, the enzyme seems to be degraded very quickly when the growing bacteria enter the stationary phase. For this reason, consumption of substrate was monitored spectroscopically at $310 \mathrm{~nm}$ in the growth medium and $5 \mathrm{mM}$ anthranilate was added one, two or three times at appropriate times to keep the concentration between $1-10 \mathrm{mM}$. Harvesting was carried out as quickly as possible under cooling.

Enzyme purification. 2-Aminobenzoyl-CoA monooxygenase was purified essentially according to the procedure described previously (Buder and Fuchs, 1989), except for the addition of $10 \mu \mathrm{M}$ phenylmethylsulfonyl and $1 \mu \mathrm{M}$ FAD at all stages before application to the DEAE-Biogel A column.

Enzyme assays. Two standard assays were used to determine $\mathrm{ABzCoA}-\mathrm{M} / \mathrm{R}$ activity. In both cases the conversion of substrate(s) was followed spectrophotometrically at $37^{\circ} \mathrm{C}$. The first is that described by Buder and Fuchs (1989). However, attention should be drawn to the observation that with fully (re)constituted holo-ABzCoA-M/R formation of the non-reduced, aromatic product $\mathrm{ABzOHCoA}$ with a $\lambda_{\max }$ at $379 \mathrm{~nm}$ (Ziegler et al., 1987) could not be observed when the enzyme concentration was high enough to yield essentially complete $\mathrm{ABzCoA}$ conversion within $\approx 3$ min. Thus, a different molar absorption coefficient of $\varepsilon_{365}=11800 \mathrm{M}^{-1} \mathrm{~cm}^{-1}$ was used, based on the consumption of $2 \mathrm{~mol} \mathrm{NADH}\left(\varepsilon_{365}=3400 \mathrm{M}^{-1} \mathrm{~cm}^{-1}\right) / \mathrm{mol}$ and $1 \mathrm{~mol} \mathrm{ABzCoA}\left(\varepsilon_{365}=5500 \mathrm{M}^{-1} \mathrm{~cm}^{-1}\right) / \mathrm{mol}$ (Buder et al., 1989; Langkau et al., 1990). [NADH] was chosen as $200 \mu \mathrm{M}$, a concentration which was found to be saturating.

Using the second, MalNEt assay, consideration has to be given to the fact that MalNEt is an electron acceptor as well as an inhibitor of $\mathrm{ABzCoA}-\mathrm{M} / \mathrm{R}$. This causes initial rates to become smaller with time and this, in turn, causes this assay to be less accurate than the $\mathrm{ABzCOA}$ assay. Hence the MalNEt assay was used preferentially to monitor enzyme activities during the purification procedure. The reaction mixture contained $100 \mu \mathrm{M}$ NADH and $1 \mathrm{mM}$ MalNEt in $100 \mathrm{mM}$ potassium phosphate pH 7.8 and was started by addition of cell-free extract or of purified enzyme. The reaction was monitored by the consumption of NADH at $340 \mathrm{~nm}\left(\varepsilon_{340}=6220 \mathrm{M}^{-1} \mathrm{~cm}^{-1}\right)$ or, for the steadystate analysis, fluorimetrically as decrease of NADH fluorescence. One unit of activity is defined as the amount of enzyme required to catalyze the oxidation of $1 \mu \mathrm{mol} \mathrm{NADH} \cdot \min ^{-1}$ under the conditions specified.

Enzymatic synthesis. 2-Aminobenzoyl-CoA (anthraniloyl$\mathrm{CoA}$ ) and 2 -amino $\left[5^{2} \mathrm{H}\right]$ benzoyl-CoA were synthesized enzymically using a CoA ligase, which is induced in the same organism as $\mathrm{ABzCoA}-\mathrm{M} / \mathrm{R}$ (Ziegler et al., 1987). For this synthesis $(\mathrm{CoAS})_{2}$ in combination with a 10 -fold excess of dithiothreitol was used instead of CoASH. The product was purified as described for the substrate analogue CoA esters (see below).

Chemical synthesis. [5-2 H]Anthranilic acid. Anthranilic acid was deuterated site-specifically by reductive dehalogenation of 5-bromoanthranilic acid with sodium borodeuteride and palladium on charcoal analogously to the method of Egli (1968). A deuterium substitution $\geq 85 \%$ was estimated from integration of aromatic signals in the ${ }^{1} \mathrm{H}-\mathrm{NMR}$ spectrum.

Benzoyl-CoA (derivatives). Synthesis of substrate analogue CoA esters was achieved by transesterification of the corresponding $N$-hydroxysuccinimide esters as described by Stöckigt 
and Zenk (1975). 4-Methyl-, 2-methoxy-, 4-methoxy- and unsubstituted benzoyl- $N$-hydroxysuccinimide were synthesized starting from the freshly prepared acid chlorides. However, the original reaction times $(24 \mathrm{~h})$ were reduced to less than $2 \mathrm{~h}$. Product formation and the products were analyzed by TLC, HPLC and ultraviolet/visible spectroscopy. Starting from these activated esters benzoyl-CoA and its derivatives were synthesized by the following general procedure. The $N$-hydroxysuccinimide ester $(200 \mu \mathrm{mol})$ was dissolved in $5 \mathrm{ml}$ tetrahydrofuran and added to an aqueous solution of $\mathrm{CoASH}(50 \mu \mathrm{mol})$ and $\mathrm{NaHCO}_{3}$ $(500 \mu \mathrm{mol})$, which was stirred at $25^{\circ} \mathrm{C}$ and flushed with nitrogen. The reaction was followed by analytical HPLC. When CoASH was consumed completely (generally within $2-3 \mathrm{~h}$ ) the reaction mixture was acidified with $1 \mathrm{M} \mathrm{HCl}$ to $\mathrm{pH} \approx 3$ and extracted with diethylether $(10 \mathrm{ml})$. The aqueous phase was neutralized ( $\mathrm{pH}$ 6) with concentrated $\mathrm{LiOH}$ and lyophilized. The CoA thioester was isolated by preparative HPLC.

Determination of absorption coefficients. Routinely, the molar absorption coefficients of newly synthesized CoA thioesters were estimated by the method of Ellman (1959). A solution of the CoA thioester $(900 \mu \mathrm{l})$ in $20 \mathrm{mM}$ potassium phosphate $\mathrm{pH} 8.0$ and $1 \mathrm{M} \mathrm{NaOH}(100 \mu \mathrm{l})$ was saturated with argon prior to, and sealed immediately after, mixing in order to avoid any oxidation of the CoASH formed. Esterolysis was followed by recording ultraviolet spectra with time. The observed rates in $0.1 \mathrm{M} \mathrm{NaOH}$ varied between $0.14 \mathrm{~min}^{-1}$ and $0.009 \mathrm{~min}^{-1}$ for 4$\mathrm{CH}_{3}-\mathrm{BzCoA}$ and for $\mathrm{ABzOHCoA}$, respectively. After completion of hydrolysis the reaction mixture was adjusted to $\mathrm{pH} 8.0$

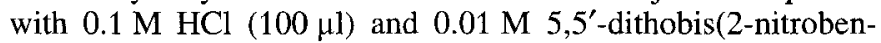
zoic acid) $(20 \mu \mathrm{l})$ was added. The absorption coefficient of the original CoA thioester was calculated from the $p$-nitrothiophenol anion absorbance at $412 \mathrm{~nm}\left(\varepsilon_{412}=13600 \mathrm{M}^{-1} \mathrm{~cm}^{-1}\right)$, which resulted from the reaction with CoASH.

Chromatography. FPLC separation of highly purified native enzyme was performed on a Pharmacia system with LKB 2150 HPLC pump, LKB 2152 HPLC controller and LKB 2210 variable wavelength monitor. Protein elution was monitored at $280 \mathrm{~nm}$. For analytical and preparative purposes a Mono Q 5/5 (flow rate $1.5 \mathrm{ml} / \mathrm{min}$ ) or a Mono $\mathrm{Q} 10 / 10$ column $(5 \mathrm{ml} / \mathrm{min}$ ) was used. They were equilibrated with $50 \mathrm{mM}$ Tris/ $\mathrm{HCl} \mathrm{pH} 7.5$ containing $0.02 \mathrm{mM}$ EDTA and $0.02 \mathrm{mM}$ dithioerythritol (buffer A). Buffer $\mathrm{B}$ contained $1 \mathrm{M} \mathrm{NaCl}$ in buffer A. Five fractions were isolated by chromatography on preparative Mono $Q$ and marked as indicated in Fig. 3. The formation of species 2 from fractions 1 and 3 was studied by mixing and storing the latter at $4^{\circ} \mathrm{C}$ in $50 \mathrm{mM}$ Tris $/ \mathrm{HCl} \mathrm{pH} 7.5$ containing $0.02 \mathrm{mM}$ EDTA and $0.02 \mathrm{mM}$ dithioerythritol. Aliquots were analyzed with time by chromatography on Mono Q 5/5.

CoA-thioesters were routinely analyzed by HPLC using an RP-18 LiChrospher column ( $250 \mathrm{~mm} \times 4 \mathrm{~mm}$; Merck) and a gradient of $10-45 \%$ (by vol.) aqueous methanol $(95 \%$ ) in $20 \mathrm{mM}$ sodium phosphate $\mathrm{pH}$ 6.0. The CoA-thioesters were purified by preparative HPLC using an RP-18 Spherisorb column $(250 \mathrm{~mm} \times 20 \mathrm{~mm}$; Bischoff, Leonberg, FRG) and a gradient of $20-55 \%$ (by vol.) in the same solvent system.

Analysis of products. Solutions of NADH $(200 \mu \mathrm{M})$ and $\mathrm{ABzCoA}(100 \mu \mathrm{M})$ were reacted under standard assay conditions (Buder and Fuchs, 1989) with purified $\mathrm{ABzCoA}-\mathrm{M} / \mathrm{R}$ and each of the three main enzyme fractions obtained from Mono $\mathrm{Q}$. For analysis of the product distribution between $\mathrm{ABzOHCoA}$ and $\mathrm{A}(\mathrm{OH}) \mathrm{H}_{2} \mathrm{CoA}$, the enzyme was separated by Centricon ultrafilters (Amicon) and the reaction mixture was purified by HPLC as described for the CoA esters.

Binding of FAD. The $K_{\mathrm{d}}$ for FAD binding was studied using the method of Dixon and Kleppe (1965) by assaying ABzCoA$\mathrm{M} / \mathrm{R}$ activity at $37^{\circ} \mathrm{C}$ as function of time upon preparing dilu- tions of enzyme at concentrations in the range $1-0.01 \mu \mathrm{M}$. The $K_{\mathrm{d}}$ was determined by comparing the activity measured at the end of changes with the initial activity. The velocity of FAD dissociation was estimated from the initial rate of decrease of activity.

Reduction/reoxidation experiments. All reduction and reoxidation experiments were performed in $50 \mathrm{mM}$ sodium or potassium phosphate $\mathrm{pH} 7.4$ at $4^{\circ} \mathrm{C}$. For anaerobiosis $0.8-1 \mathrm{ml}$ freshly filtered $(0.45-\mu \mathrm{m}$ filters from Millipore Corp.) enzyme solution was placed in the main compartment of an anaerobic cuvette. Small volumes, typically $20 \mu \mathrm{l}$ of the reductant and/or oxidant, were present in the sidearm(s). The cell was made anaerobic at $0^{\circ} \mathrm{C}$ by up to eight cycles of evacuation and flushing with purified argon. The cell was kept under vacuum during the experiments unless oxygen was admitted at the times indicated. Anaerobic reactions were started by mixing the reactant, i.e. $\mathrm{NADH}$ or MalNEt from one sidearm. Spectral changes were followed spectrophotometrically and those which occurred within the mixing time are represented by dashed lines in Figs 6 , 7 , and 8 . EDTA $/ h v$ reductions were performed at $4{ }^{\circ} \mathrm{C}$ using a 250 -W halogen lamp at a distance of $\approx 15 \mathrm{~cm}$ and irradiation periods $\leqslant 1$ min using the set-up described earlier (Massey et al., 1978).

Instrumentation. Absorption spectra and single-wavelength kinetics were recorded either with a Kontron-Uvikon 920 spectrophotometer or with a Hewlett-Packard 8452A diode array detector. HPLC and ${ }^{1} \mathrm{H}-\mathrm{NMR}$ measurements were made as described earlier (Langkau et al., 1990). Fluorescence was measured with a Kontron SFM-25 fluorimeter.

\section{RESULTS}

Stability. While the enzyme is stable when stored in liquid nitrogen, when kept as a micomolar solution, at $\mathrm{pH} 7.8$ and at $0^{\circ} \mathrm{C}$ or $25^{\circ} \mathrm{C}$ it gradually looses activity with an apparent $t_{1 / 2} \approx 2$ days. No apparent stabilization is achieved in the presence of substrate $\mathrm{ABzCoA}, \mathrm{NADH}$ or FAD. In dilute solution $(\approx 10 \mathrm{nM})$ and at $25^{\circ} \mathrm{C}$ the loss of activity has a $t_{1 / 2} \approx 2 \mathrm{~min}$, which is substantially enhanced $\left(t_{1 / 2} \approx 1-1.3 \mathrm{~min}\right)$ in the presence of $2 \mathrm{mM}$ MalNEt. At this dilution the presence of $\approx 100 \mu \mathrm{M}$ concentrations of either NADH, ABzCoA or FAD enhances stability considerably $\left(t_{1 / 2} \approx 30 \mathrm{~min}\right)$. These results suggest that inactivation is connected with loss of FAD cofactor (cf. also below) and that MalNEt is an inactivator probably reacting preferentially with the apo-protein.

Substrate and effector specificity. The catalytic velocity of $\mathrm{NADH}$ consumption in the presence of $\mathrm{ABzCoA}$ (Scheme 1, structure I) and a number of analogous CoA thioesters was studied by initial rate measurements under aerobic conditions (Table 1). Highest rates were found with $\mathrm{ABzCOA}$ and [5$\left.{ }^{2} \mathrm{H}\right] \mathrm{ABzCoA}$, corresponding to an $\approx 150$-fold enhancement compared to the oxidase activity of unliganded enzyme. A significant acceleration was also observed with the 2-hydroxy analog of $\mathrm{ABzCoA}$ (2-OH-BzCoA) (40-fold) and $\mathrm{ABzOHCoA}$ (20fold), while $\mathrm{BzCoA}$ and the 4-fluoro analog (4-F-BzCoA) showed only relatively small effects. With other analogs, 4- $\mathrm{CH}_{3}-$ $\mathrm{BzCoA}$, 3- $\mathrm{NH}_{2}-\mathrm{BzCoA}, 4-\mathrm{NH}_{2}-\mathrm{BzCoA}$, 4-OH-BzCoA, 2$\mathrm{OCH}_{3}-\mathrm{BzCOA}$ and $4-\mathrm{NO}_{2}$-phenylacetyl-CoA, the velocity of NADH oxidation was enhanced less than 2-fold. In order to distinguish between substrates and non-substrate effectors the extent of conversion was analyzed by HPLC. Only $\mathrm{ABzCoA}$ and $\left[5-{ }^{2} \mathrm{H}\right] \mathrm{ABzCoA}$ were converted completely, yielding 2-amino-5oxocyclohex-1-enecarboxyl-CoA as the main product (Langkau et al., 1990). $2-\mathrm{OH}-\mathrm{BzCoA}$ is converted to $\approx 10 \%$ into a product 
Table 1. Consumption of NADH and production of $\mathrm{H}_{2} \mathrm{O}_{2}$ by ACoA$M / R$ in the presence of substrate and non-substrate effectors. $V_{\max }$ is defined as the consumption of NADH in incubations containing $100 \mu \mathrm{M}$ substrate/effector, $200 \mu \mathrm{M} \mathrm{NADH}$ and $60 \mathrm{nM} \mathrm{E} \sim(\mathrm{FAD})_{2}$ in $100 \mathrm{mM}$ potassium phosphate $\mathrm{pH} 7.8$ at $25^{\circ} \mathrm{C}$. The decrease in absorbance was followed at $365 \mathrm{~nm}$ using $\Delta \varepsilon_{365}=3.18 \mathrm{mM}^{-1} \mathrm{~cm}^{-1}$ for the consumption of NADH with non-substrate effectors or $\Delta \varepsilon_{365}=5.93 \mathrm{mM}^{-1} \mathrm{~cm}^{-1}$ for the conversion of $1 \mathrm{~mol} \mathrm{NADH} / 0.5 \mathrm{~mol} \mathrm{ABzCoA}$ or $\left[5-{ }^{2} \mathrm{H}\right] \mathrm{ABzCoA}$, respectively. One unit (U) is defined as mol NADH oxizied $\cdot \min ^{-1}$. mol enzyme dimer ${ }^{-1}$. Samples were withdrawn before and after the reaction and analyzed by HPLC for consumption of the thest compound. The production of $\mathrm{H}_{2} \mathrm{O}_{2}$ due to the effectors is the difference in oxygen detection between a reaction performed in the presence of catalase and one in the absence. In the second case catalase was also added upon completion of the $\mathrm{ABzCoA}-\mathrm{M} / \mathrm{R}$-catalyzed reaction and the amount of oxygen produced secondarily correlated to that of $\mathrm{H}_{2} \mathrm{O}_{2}$. Conditions: cells contained $100 \mu \mathrm{M} \mathrm{NADH}, 130 \mu \mathrm{M}$ effector and $\approx 1400 \mathrm{U}$ catalase in $100 \mathrm{mM}$ potassium phosphate $\mathrm{pH} 7.8$ in a final volume of $2.1-2.2 \mathrm{ml}$. Reactions were initiated by addition of $0.12-0.24 \mathrm{nmol} \mathrm{ABzCoA}-\mathrm{M} / \mathrm{R}$; n.d. $=$ not determined.

\begin{tabular}{lcll}
\hline Substrate/effector & $V_{\text {max }}$ & $\begin{array}{l}\text { Mono- } \\
\text { oxygenation }\end{array}$ & $\begin{array}{l}\text { Formation } \\
\text { of } \mathrm{H}_{2} \mathrm{O}_{2}\end{array}$ \\
\hline None & $\mathrm{U}$ & & $\%$ \\
ABzCoA & 5 & & n.d. \\
[5- $\left.{ }^{2} \mathrm{H}\right] \mathrm{ABzCoA}$ & 824 & +++ & 0 \\
2-OH-BzCoA & 817 & +++ & $10 \pm 4$ \\
$\mathrm{ABz}(\mathrm{OH}) \mathrm{CoA}$ & 214 & + & $92 \pm 2$ \\
$\mathrm{BzCoA}$ & 112 & $+/-$ & $91 \pm 7$ \\
4-F-BzCoA & 33 & - & $94 \pm 6$ \\
\hline
\end{tabular}

which has a shorter retention time on RP-18 HPLC indicating a higher polarity, and which might be a dihydroxybenzoyl-CoA ester. The partial conversion of $\mathrm{ABzOHCoA}$ is attributed to spontaneous hydrolysis of the CoA ester rather than to hydroxylation. A possible hydrogenation of $\mathrm{ABzOHCoA}$ (Scheme 1, III) to form e.g. 2-amino-5-oxocyclohex-1-enecarboxyl CoA (Scheme 1, IV) is very unlikely, as judged from absorption spectra of the product mixture. $\mathrm{BzCoA}$ and $4-\mathrm{F}-\mathrm{BzCoA}$ remained entirely unaffected during NADH oxidation. Some substrate analogs are known to promote NADH consumption to form $\mathrm{H}_{2} \mathrm{O}_{2}$ without monooxygenation (uncoupling, White-Stevens and Kamin, 1970). The uncoupling of NADH consumption from hydroxylation in the cases listed in Table 1 was verified by the procedure of White-Stevens and Kamin (1970). In agreement with product analysis by $\mathrm{HPLC} \mathrm{BzCoA}, 2-\mathrm{OH}-$ $\mathrm{BzCoA}$ and $\mathrm{ABzOHCoA}$ yielded an almost $50 \%$ reformation of $\mathrm{O}_{2}$ from $\mathrm{H}_{2} \mathrm{O}_{2}$ upon addition of catalase (Table 1), which is consistent with a predominantly 'non-substrate' or 'effector' activity. With $\mathrm{ABzCoA}$ no formation of $\mathrm{H}_{2} \mathrm{O}_{2}$ could be detected while with its deuterated form $\left[5^{-2} \mathrm{H}\right] \mathrm{ABzCoA}$ traces of $\mathrm{H}_{2} \mathrm{O}_{2}$ were found.

Binding of the substrate $\mathrm{ABzCoA}$ and of analogs to oxidized and reduced $\mathrm{ABzCoA}-\mathrm{M} / \mathbf{R}$. The addition of $\mathrm{ABzCOA}$ to oxidized enzyme causes large and marked perturbations of the visible absorption spectrum of the flavin chromophore (Fig. 1A). The spectral changes observed consist of two phases. The first one is essentially complete experimentally at a $\approx 1.2$-fold excess of $\mathrm{ABzCoA}$ compared to enzyme-bound flavin, while the second is not saturated at a 12-fold excess and shows an apparent $K_{\mathrm{d}} \approx 700 \mu \mathrm{M}$. Since the $K_{\mathrm{m}}$ for $\mathrm{ABzCoA}$ has been reported to be $<25 \mu \mathrm{M}$ and substrate inhibition occurs at $[\mathrm{ABzCoA}]>150 \mu \mathrm{M}$ (Buder et al., 1989), it is likely that the weak binding has no catalytic relevance, but is associated with inhibition. Titration
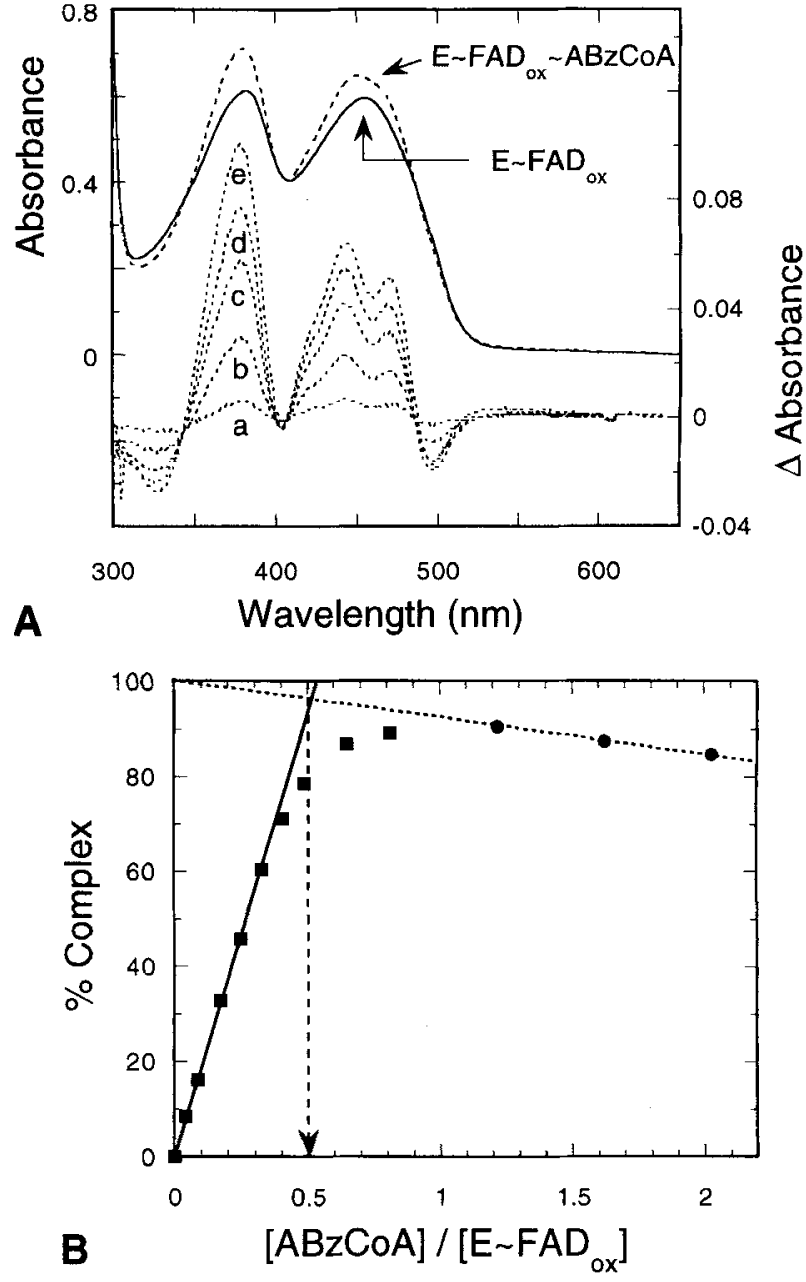

Fig. 1. Binding of $\mathrm{ABzCoA}$ to oxidized $\mathrm{ABzCoA}-\mathrm{M} / \mathrm{R}\left(\mathrm{E} \sim \mathbf{F A D}_{\mathrm{ox}}\right)$. (A) Spectral perturbations accompanying binding. Conditions: $53 \mu \mathrm{M}$ enzyme-bound flavin ( $E \sim F A D), 0.1 \mathrm{mM}$ EDTA in $1.0 \mathrm{ml} 50 \mathrm{mM}$ sodium phosphate $\mathrm{pH} 7.4$ at $4^{\circ} \mathrm{C}$. All spectra were recorded versus an equal concentration of substrate in the reference cuvette and are corrected for dilution. The scale on the left ordinate corresponds to the spectra of oxidized $\mathrm{ABzCoA}-\mathrm{M} / \mathrm{R}$ before $(-)$ and upon addition of $63 \mu \mathrm{M} \mathrm{ABzCoA}$ (1.2-fold molar excess) (-- ). Calculated difference spectra $\mathrm{a}-\mathrm{e}(\cdots \cdots)$ were obtained upon additions of $2.3 \mu \mathrm{M}, 8.9 \mu \mathrm{M}$, $17 \mu \mathrm{M}, 25 \mu \mathrm{M}$, and $63 \mu \mathrm{M} \mathrm{ABzCoA}$ (right ordinate scale). Peak maxima of positive absorbance changes were at 471,443 and $378 \mathrm{~nm}$, and of negative changes at 497 and $327 \mathrm{~nm}$. Isosbestic points were at 487, 408, 401 and $346 \mathrm{~nm}$. Addition of $\approx 600 \mu \mathrm{M} \mathrm{ABzCoA}$ resulted in a second set of difference spectra characterized by decreasing absorbance changes at all maxima shown, except for that at $378 \mathrm{~nm}$ (not shown). See text for further details. (B) Stoichiometry of binding. Data obtained from similar experiments are plotted as the percentage of complete complex formation $\left(\mathrm{E} \sim \mathrm{FAD}_{\mathrm{ox}} \sim \mathrm{ABzCoA}\right)$ versus the ratio $[\mathrm{ABzCoA}] /$ $\left[\mathrm{E} \sim \mathrm{FAD}_{\mathrm{ox}}\right] .100 \% \mathrm{E} \sim \mathrm{FAD}_{\mathrm{ox}} \sim \mathrm{ABzCoA}$ for the first binding site was estimated from back-extrapolation of the absorbance changes at $443 \mathrm{~nm}$ occurring in the second phase (-- ) which reflects binding of further $\mathrm{ABzCoA}$ to a second site $(-$ ). Spectral perturbations resulting from substoichiometric additions of $\mathrm{ABzCOA}$ and binding to the first site are also shown (ם)

with $\mathrm{ABzCoA}$ indicates a stoichiometry of only $0.5 \mathrm{~mol}$ $\mathrm{ABzCoA} / \mathrm{mol}$ enzyme flavin for the primary binding and a $K_{\mathrm{d}} \leqslant 1 \mu \mathrm{M}$ (Fig. 1B). Additions of $\mathrm{ABzCoA}$ to $\mathrm{E} \sim \mathrm{FADH}_{2}$ also caused spectral perturbations compatible with binding to a halfsite (Fig. 2) and a $K_{\mathrm{d}} \leqslant 2 \mu \mathrm{M}$. It is most important to note that fully reduced $\mathrm{ABzCoA}-\mathrm{M} / \mathrm{R}$ does not react with (hydrogenate) $\mathrm{ABzCoA}$. 


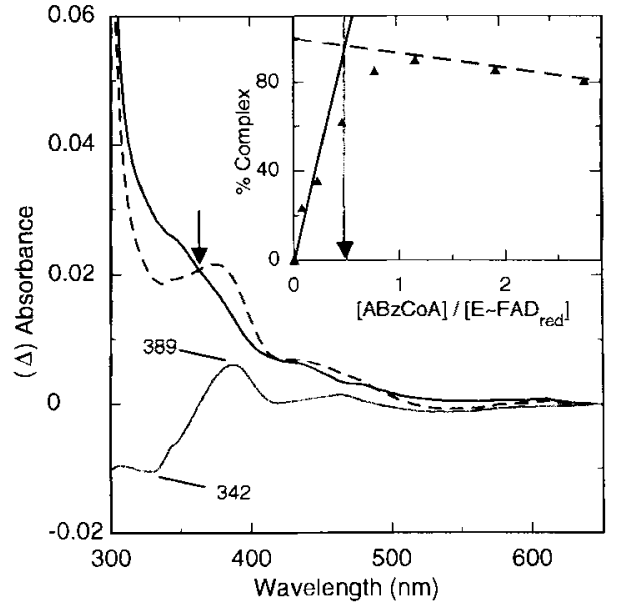

Fig. 2. Binding of $\mathrm{ABzCoA}$ to reduced $\mathrm{ABzCoA}-\mathrm{M} / \mathbf{R}\left(\mathbf{E} \sim \mathrm{FAD}_{\mathrm{red}}\right)$. (-) Absorbance of uncomplexed $\mathrm{E} \sim \mathrm{FAD}_{\mathrm{red}} ;(--)$ absorbance of $\mathrm{E} \sim \mathrm{FAD}_{\mathrm{rcd}} \sim \mathrm{ABzCoA}$ complex obtained upon addition of $1.1 \mathrm{~mol}$ $\mathrm{ABzCoA} / \mathrm{mol}$ complex; lower curve, the difference spectrum between the preceding two. The arrow indicates an isosbestic point at $355 \mathrm{~nm}$. The insert shows the determination of the stoichiometry of $\mathrm{ABzCoA}$ binding done as outlined in the legend of Fig. 1. The absorbance changes between $389 \mathrm{~nm}$ and $342 \mathrm{~nm}$ were used for the estimation of $100 \%$ $\mathrm{E} \sim \mathrm{FAD}_{\text {red }} \sim \mathrm{ABzCoA}$ complex. Conditions: $17.3 \mu \mathrm{M} \mathrm{E} \sim \mathrm{FAD}$ (enzyme-bound flavin), containing $10 \mathrm{mM}$ EDTA, $0.5 \mu \mathrm{M}$ 5-deazariboflavin, $100 \mu \mathrm{M}$ protocatechuate and $0.46 \mathrm{mU}$ protocatechuate dioxygenase in $50 \mathrm{mM}$ potassium phosphate $\mathrm{pH} 7.4$ under anaerobic conditions. The solution was stored overnight in order to consume residual oxygen in the system and and was then illuminated until the spectral changes accompanying reduction were complete. $\mathrm{ABzCoA}$ in an argonsaturated solution was then added with a syringe through a septum in seven portions yielding a final $[\mathrm{ABzCoA}]=47.5 \mu \mathrm{M}$. The presence of traces of oxygen required occasional irradiation upon addition of $\mathrm{ABzCOA}$ in order to restore full reduction. This might have caused turnover of up to $20 \%$ of the total $[\mathrm{ABzCOA}]$ and thus a corresponding error in the $K_{\mathrm{d}}$ determination. The estimated apparent $K_{\mathrm{d}} \leqslant 1.8 \mu \mathrm{M}$ is therefore an upper limit.

The substrate analogs $\mathrm{BzCoA}, 2-\mathrm{OH}-\mathrm{BzCoA}$ and the product $\mathrm{ABzOHCoA}$ also bind to oxidized $\mathrm{ABzCoA}-\mathrm{M} / \mathrm{R}$ and perturb its absorption spectrum. $0.5 \mathrm{~mol} \mathrm{BzCoA}$ binds to $1 \mathrm{~mol}$ ABzCoA-M/R dimer with a $K_{\mathrm{d}} \approx 19 \mu \mathrm{M}$ and to the second site with $K_{\mathrm{d}} \approx 330 \mu \mathrm{M}$. With $\mathrm{ABzOHCoA}$ the first binding step has the same stoichiometry and a $K_{\mathrm{d}} \approx 1 \mu \mathrm{M}$, the second was substantially larger, but could not be determined due to the low quantity of material available. With 2-OH-BzCoA the spectral perturbations observed are also compatible with a biphasic binding and with a stoichiometry of $0.5 \mathrm{~mol} / \mathrm{mol} \mathrm{ABzCoA}-\mathrm{M} / \mathrm{R}$ dimer, however they do not allow a determination of the second step probably due to a very large $K_{\mathrm{d}}$.

\section{Resolution of purified ABzCoA-M/R by chromatography on} Pharmacia Mono $Q$ anion exchanger and FAD binding. Fig. 3 shows a typical profile observed when pure $\mathrm{ABzCoA}$ $M / R$ was eluted from a preparative Mono $Q$ anionic-exchange column. Three major fractions designated 1,2 and 3 , with a relative absorbance ratio of approx. 1:2:1 were observed, which correspond to what has been described previously by Buder and Fuchs (1989). However, two further minor species (fractions 1a, 2a) were also observed. All five fractions exhibited ABzCoA$\mathrm{M} / \mathrm{R}$ activity. Upon mixing fractions 1 and 3 , the conversion of part of the protein to species 2 occurs as shown in Fig. 4. This is in agreement with the finding of Buder and Fuchs (1989) that rechromatography of species 2 yields an elution profile qualitatively as shown in Fig. 3, i.e. that species 2 can yield species 1

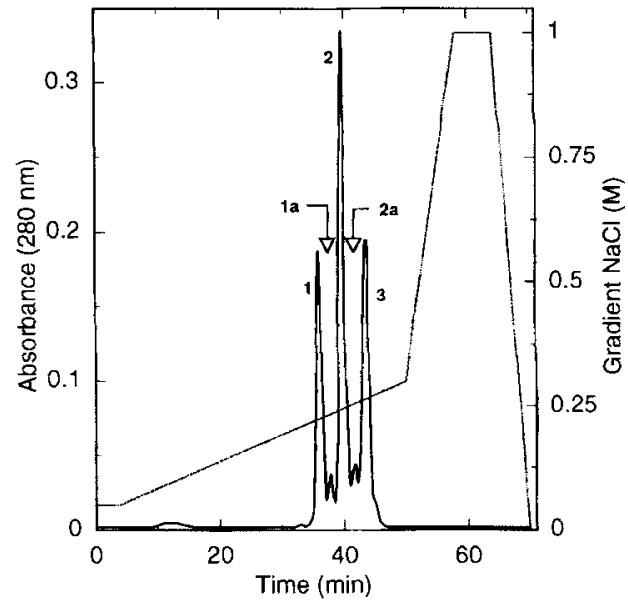

Fig. 3. Fast protein liquid chromatography on Pharmacia Mono $Q$ of purified ABzCoA-M/R. $5 \mathrm{mg}$ highly purified native enzyme obtained as described in Materials and Methods was chromatographed on a Mono Q 10/10 column. Starting buffer A: $50 \mathrm{mM}$ Tris/ $\mathrm{HCl} \mathrm{pH} 7.5$ containing $0.02 \mathrm{mM}$ EDTA and $0.02 \mathrm{mM}$ dithioerythritol; buffer B : buffer A plus $1 \mathrm{M} \mathrm{NaCl}$. Flow rate $5 \mathrm{ml} / \mathrm{min}$. Gradient as shown by the dashed line. Three major (1, 2 and 3$)$ and two minor (1a, 2a) protein peaks were collected separately.

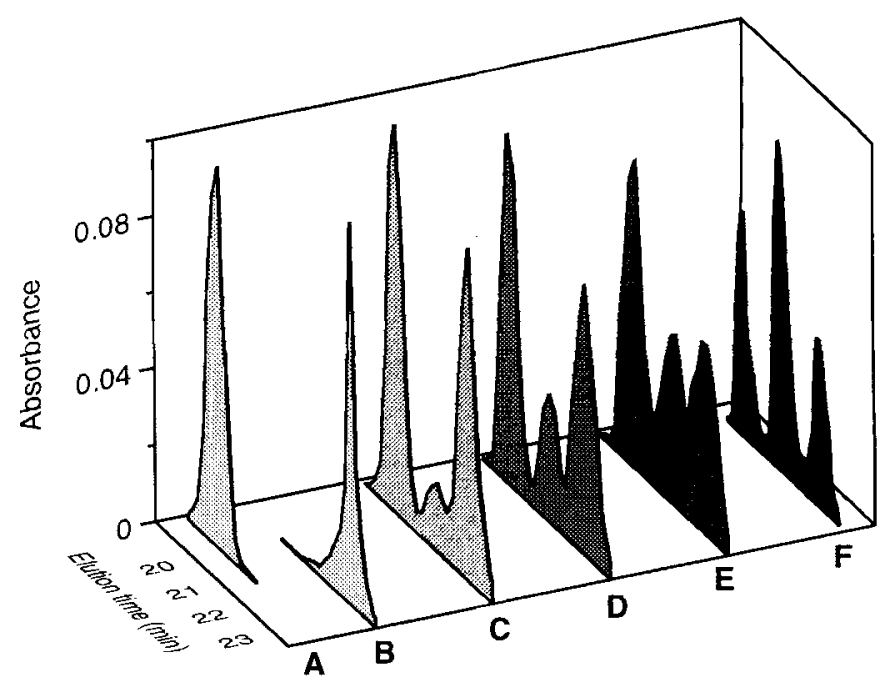

Fig. 4. Recombination of $\mathrm{ABzCoA}-\mathrm{M} / \mathrm{R}$ species 1 and 3 to form species 2. The purity of isolated species 1 and 3 , obtained as described in Fig. 3 (see also text for details), is shown by chromatograms A and B. These species were mixed in approximately equal amounts in buffer $\mathrm{A}$ at $4{ }^{\circ} \mathrm{C}$ and the incubation analyzed immediately upon mixing $(t=0 \mathrm{~h}$, profile C), and at $t=45 \mathrm{~h}$ (D) and $96 \mathrm{~h}$ (E). At longer incubation times some protein denaturation occurs. The profile of native untreated enzyme is shown for comparison $(\mathrm{F})$.

and 3. Treatment of $\mathrm{ABzCoA}-\mathrm{M} / \mathrm{R}$ with either a 10 -fold excess of $\mathrm{H}_{2} \mathrm{O}_{2}$ for $12 \mathrm{~h}$ or a 100 -fold excess of dithioerythritol for $24 \mathrm{~h}$, both at $4^{\circ} \mathrm{C}$, did not modify the elution profile. The $\mathrm{H}_{2} \mathrm{O}_{2}$ treatment, however, essentially abolished activity and both the absorption and fluorescence spectra of FAD were affected. Six SHgroups (three pairs) react with $3 \mathrm{~mol} 5,5^{\prime}$-dithiobis(2-nitrobenzoic acid)/mol ABzCoA-M/R monomer, with complete loss of activity and of FAD binding, as determined by ultrafiltration.

The three main species contained in peaks 1,2 and 3 differ markedly in their specific activities and in their ratios of absorption $A_{280 / 450}$, which reflects the proportion of holo- to apo-protein (Table 2). For the best fractions of ABzCoA-M/R obtained from 
Table 2. Specific activity of $\mathrm{ABzCoA}-\mathrm{M} / \mathrm{R}$ species 1,2 and 3 and comparison with FAD content. The FAD content was measured as the $A_{280 / 450 \mathrm{~mm}}$ ratio). Species are as defined in Fig. 3, specific activity as defined in Table 1. Reconstitution was performed by incubation at $25^{\circ} \mathrm{C}$ for 10 min with a 100 -fold molar excess of FAD to obtain full FAD content.

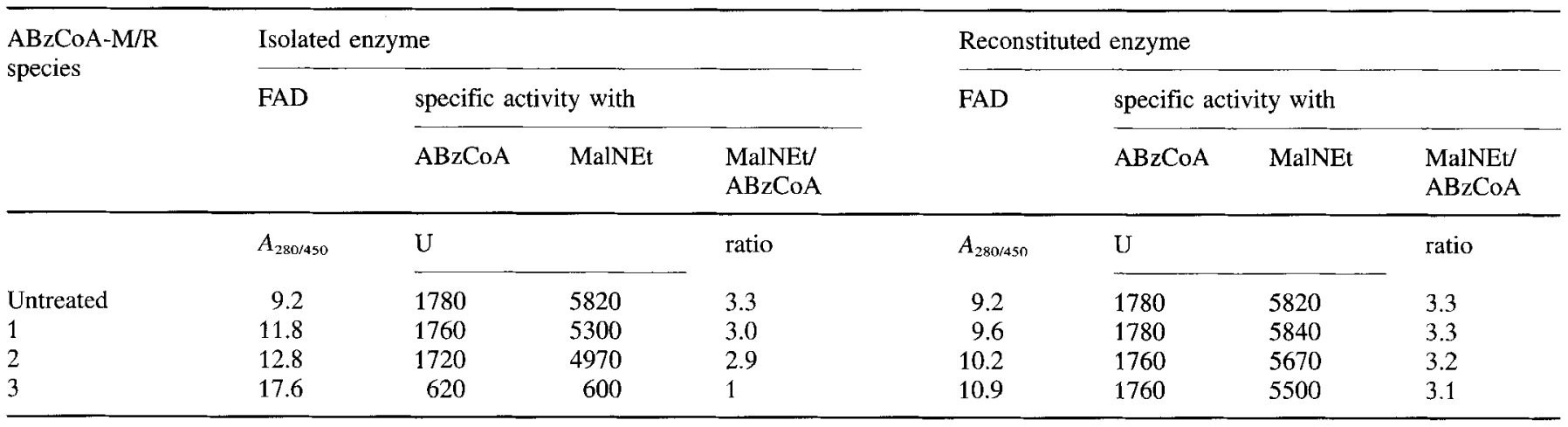

hydroxyapatite, which were not chromatographed on Mono Q, the $A_{280 / 450}$ was typically 9.2. This ratio increases from species 1 to 3 suggesting a decrease of FAD content. Thus fraction 3 can be estimated to contain $50-55 \% \mathrm{FAD}\left(A_{280 / 450}=17.6\right)$ as compared to $\mathrm{ABzCoA}-\mathrm{M} / \mathrm{R}$ before Mono-Q chromatography. Surprisingly, the specific activities of the three $\mathrm{ABzCoA}-\mathrm{M} / \mathrm{R}$ fractions, calculated on the basis of the FAD content, differ from those of unresolved enzyme when measured either with MalNEt or with $\mathrm{ABzCoA}$ as substrate: Fraction 3 has only $\approx 10 \%$ of the MalNEt and $\approx 30 \%$ of the $\mathrm{ABzCoA}$ activity compared to unresolved enzyme. Hence, the ratio of the specific activities found for MalNEt/ABzCoA dropped from 3.3 for untreated enzyme to 1.0 for fraction 3 , fractions 1 and 2 being intermediate cases (cf. Table 2). This is in agreement with the finding of Buder and Fuchs (1989) that rechromatography of species 2 yields an elution profile qualitatively as shown in Fig. 3, i.e. that species 2 can yield species 1 and 3 .

Most importantly there is a difference in the product distribution when $\mathrm{ABzCoA}$ is turned over by untreated $\mathrm{ABzCoA}-\mathrm{M} / \mathrm{R}$ compared to fractions 1, 2 or 3 (Table 2). Products were separated from $\mathrm{NAD}^{+} / \mathrm{NADH}$ and $\mathrm{ABzCoA}-\mathrm{M} / \mathrm{R}$ and analyzed as shown in Fig. 5. Turnover of $\mathrm{ABzCoA}$ (I) using unresolved $\mathrm{ABzCoA}-\mathrm{M} / \mathrm{R}$ appears to yield essentially the normal product $\mathrm{A}(\mathrm{OH}) \mathrm{H}_{2} \mathrm{CoA}$ (IV) while with fraction 3 the relative content of $\mathrm{ABzOHCOA}$ (III) is $\approx 60 \%$. At first glance these results suggest that species 1,2, and 3 are competent in monooxygenation, but vary in their capacity to hydrogenate. The relative differences between these activity profiles can readily be explained by loss of FAD selectively at the active site catalyzing hydrogenation. Thus ABzCoA-M/R completely depleted of FAD at its 'hydrogenation site' should catalyze only formation of $\mathrm{ABzOHCoA}$ (III). In agreement with this we find mainly $\mathrm{ABzOHCoA}$ (III) formation (up to 60\%) using fraction 3. FAD 'loss' by species 1,2 and 3 could be reversed by incubation with a 100 -fold excess of FAD for $1 \mathrm{~h}$ when activity comparable to that of native enzyme was recovered (Table 2). Using the method of Dixon and Kleppe (1965), the dissociation rate $\left(k_{\text {off }}\right)$ for FAD to yield $50 \%$ FAD-depleted enzyme was estimated as $0.7-1.5 \mathrm{~min}^{-1}$ which corresponds to the rate of inactivation of dilute enzyme solutions. The corresponding $K_{\mathrm{d}}$ for FAD dissociation was $\approx 0.06 \mu \mathrm{M}$ at $37^{\circ} \mathrm{C}$ assuming that $\approx 0.5 \mathrm{~mol} \mathrm{FAD} \mathrm{dissociate} / \mathrm{mol}$ enzyme dimer (same method, data not shown). In fact monooxygenase activity was not decreased below $\approx 30 \%$ of the initial value even at the lowest enzyme dilutions, in contrast to the hydrogenase activity.

Reduction and (re)oxidation experiments. Photoreduction. Light irradiation of $\mathrm{ABz} C o A-M / R$ in the presence of EDTA

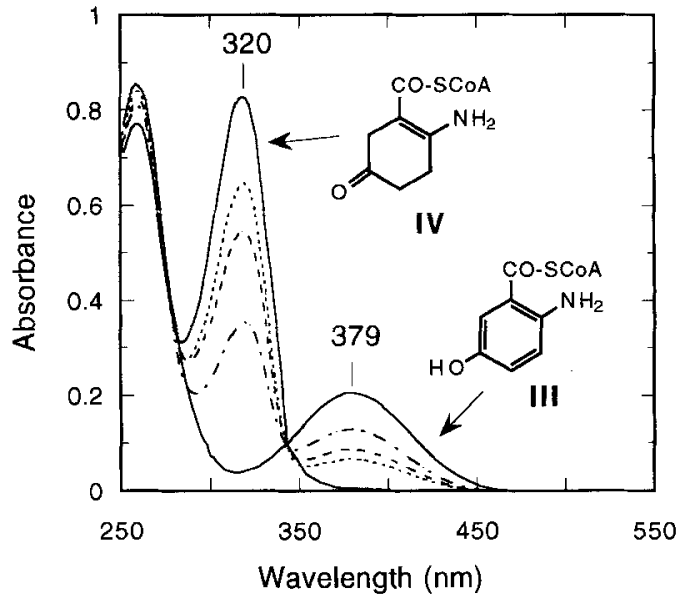

Fig. 5. Ultraviolet/visible absorption spectra of product mixtures resulting from incubations of $\mathrm{ABzCOA}$ with untreated $\mathrm{ABzCoA}-\mathrm{M} / \mathrm{R}$, and with species 1 or 3 . Product mixtures were separated from excess substrate and $\mathrm{NAD}^{+}$NADH by HPLC and analyzed subsequently by spectroscopy. Curves were obtained from incubations using $(\cdots \cdots)$ native enzyme, (-- ), species 1 and (-.-.) species 3 indicating formation of $71 \%, 62 \%$ and $39 \% \mathrm{~A}(\mathrm{OH}) \mathrm{H}_{2} \mathrm{CoA}$, respectively; (pure $\mathrm{A}(\mathrm{OH}) \mathrm{H}_{2} \mathrm{CoA}\left(\lambda_{\max }=320 \mathrm{~nm}\right)$ and of $\mathrm{ABzOHCoA}\left(\lambda_{\max }=379 \mathrm{~nm}\right)$ shown for comparison.

yields fully reduced enzyme without formation of detectable amounts of the red or blue semiquinone species as intermediates (not shown). On the basis of $\varepsilon_{454}=11.3 \mathrm{mM}^{-1} \cdot \mathrm{cm}^{-1}$ for oxidized enzyme (Buder and Fuchs, 1989), the absorption coefficient for reduced enzyme was estimated as $\varepsilon_{454}=1.84 \mathrm{mM}^{-1}$. $\mathrm{cm}^{-1}$. The presence of $1 \mu \mathrm{M} 5$-deazariboflavin enhances the rate of photoreduction as found also for other flavin enzymes (Massey and Hemmerich, 1977). Reoxidation occurs upon admission of oxygen; the kinetic course of this process will be described below.

Reduction with $N A D H$. When $\mathrm{ABzCOA}-\mathrm{M} / \mathrm{R}$ is reacted anaerobically with a 13 -fold excess of NADH in the absence of the substrate $\mathrm{ABzCoA}$ the ensuing reaction is markedly biphasic, about half the oxidized flavin absorption disappearing within the mixing time of the reactants. The reduction of the remaining half occurs at a much slower rate of $\approx 0.06 \mathrm{~min}^{-1}$ as shown in Fig. 6, curve A. In contrast, the presence of stoichiometric [ABzCoA] results in $\approx 85 \%$ reduction within the mixing time, while the residual part is reduced at about the same rate as the slow phase in the absence of $\mathrm{ABzCoA}$ (Fig. 6, curve B, $\mathbf{\Delta}$ ). The observation of $\approx 15 \%$ slow reaction is interpreted as being due 


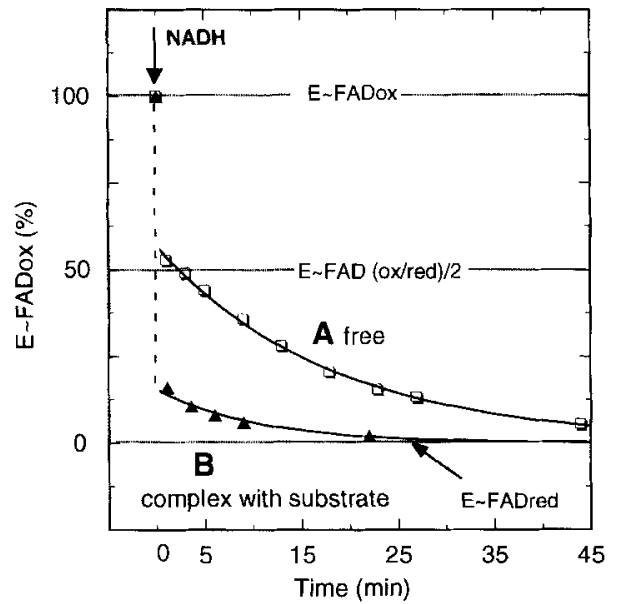

Fig. 6. Course of NADH reduction of $A B z C o A-M / R$ in the absence and presence of $\mathrm{ABzCoA}$. In experiment (A) $200 \mu \mathrm{M} \mathrm{NADH}$ (final concentration) was added from one sidearm of an anaerobic cuvette to $15.4 \mu \mathrm{M}$ enzyme $(\mathrm{E} \sim \mathrm{FAD})$ at $4^{\circ} \mathrm{C}$ and the reduction was monitored starting within 0.5 min of mixing the reactants. Almost $50 \%$ of the total absorbance of oxidized flavin measured at $454 \mathrm{~nm}$ disappeared within this mixing time $(---) ;(\square)$ the subsequent decrease; $(\longrightarrow)$ the fit of the data points assuming a pseudo-first-order reaction with $k_{\text {obs }}=0.06$ $\min ^{-1}$. The companion experiment $(B, \mathbf{A})$ was performed analogously using $10.8 \mu \mathrm{M}$ enzyme $(\mathrm{E} \sim \mathrm{FAD})$ which, however, was complexed with $11.3 \mu \mathrm{M} \mathrm{ABzCoA}$ at $4^{\circ} \mathrm{C}$. The reduction was started by adding $192 \mu \mathrm{M}$ $\mathrm{NADH}$ (final concentration) from the sidearm of the anaerobic cuvette. Bleaching of $\mathrm{E} \sim \mathrm{FAD}_{\mathrm{ox}} \sim \mathrm{ABzCoA}$ at $454 \mathrm{~nm}$ was about $85 \%$ complete within the mixing time. The residual $\approx 15 \%$ of oxidized enzyme was reduced at approximately the same rate as in the slow phase in the absence of substrate.

to the presence of the corresponding amount of uncomplexed ABzCoA-M/R. Together with the observation that one enzyme dimer binds tightly one $\mathrm{ABzCoA}$ molecule (i.e. stoichiometry of $0.5 \mathrm{~mol} \mathrm{ABzCoA} / \mathrm{mol} \mathrm{FAD}$ ), these results suggest that substrate binds to, and affects the NADH reactivity of, one specific 'half' of the enzyme flavin. In the following paper (Langkau and Ghisla, 1995) direct evidence will be presented that indeed $\mathrm{ABzCoA}$ binding does not affect the NADH reactivity of 'the other half' of the flavin population.

Reaction of reduced enzyme with oxygen in the absence of $A B z C O A$. The course of reoxidation of fully (photo)reduced, uncomplexed enzyme is also strongly biphasic (Fig. 7, A, $\square$ ), with a $1: 1$ ratio of the fast and slow phase $\left(k_{\mathrm{obs}}=0.1 \mathrm{~min}^{-1}\right)$. When $\mathrm{ABzCoA}-\mathrm{M} / \mathrm{R}$ was first reduced to $\approx 50 \%$ by addition of limited NADH and subsequently exposed to oxygen, a monophasic and slow reaction (same rate as above) was observed (Fig. 7, B, $\mathbf{\Lambda}$ ). These results are compatible with the presence of two sites which have different reactivities towards oxygen and are independent of each other. Furthermore, it can be concluded that the site which is reduced rapidly by NADH (in the absence of substrate) is the one which is reoxidized slowly by oxygen and vice versa. The same type of 'reoxidation' experiments was performed using species 1,2 and 3 (as defined in Fig. 3), which have a varying content of FAD cofactor. The results show that the percentage of enzyme flavin reacting very fast with $\mathrm{O}_{2}$ (Fig. 7, C) increases in that order, i.e. it correlates inversely with the FAD content remaining in the hydrogenation active site. This corresponds to the ratio of $\mathrm{ABzOHCoA} / \mathrm{A}(\mathrm{OH}) \mathrm{H}_{2} \mathrm{CoA}$ formed using species 1,2 and 3 , which also increases with decreasing FAD content. As an extension of the above interpretation, it can be deduced that $\mathrm{ABzCoA}-\mathrm{M} / \mathrm{R}$ has two different active sites, one catalyzing the monooxygenation which reacts very rapidly

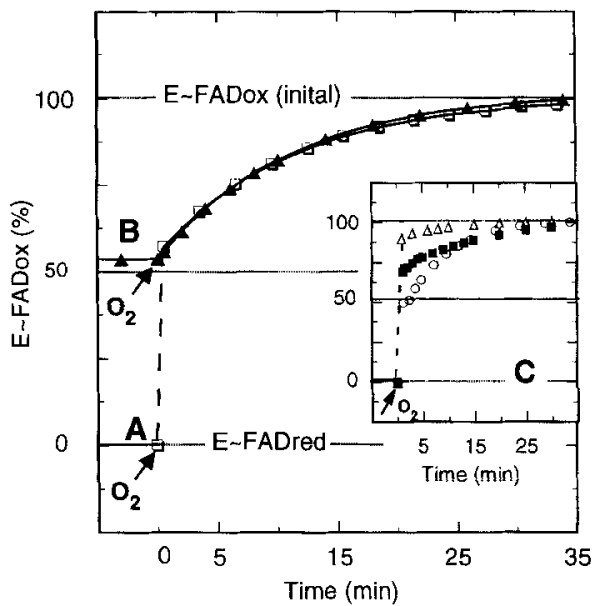

Fig. 7. Oxygen (re)oxidation of fully and-half-reduced $A B z C o A-M /$ R. (A) $8.9 \mu \mathrm{M}$ enzyme (E FAD) was made anaerobic and reduced photochemically at $4^{\circ} \mathrm{C}$ in the presence of $12 \mathrm{mM}$ EDTA. Reoxidation was initiated by admission of air to the anaerobic solution and spectral changes were followed at $454 \mathrm{~nm}$. Some $55 \%$ of the reduced enzyme, as deduced from the absorbance increase at $454 \mathrm{~nm}$, was reoxidized within the mixing time of $<0.5 \mathrm{~min}$, and the remaining with a $k_{\mathrm{obs}} \approx 0.1$ $\min ^{1}$. (-) The fit of the data points $(\square)$ assuming a pseudo-firstorder reaction. (B) Similar experiment in which enzyme was reduced to approximately $50 \%$ by titration with $\mathrm{NADH}$ before admission of $\mathrm{O}_{2}$. The observed rate of reoxidation is approximately the same as that of the slow phase in A. The insert (C) shows the traces obtained from similar experiments obtained using $\approx 20 \mu \mathrm{M}$ native enzyme $(O)$, species $2(\square)$ and $3(\triangle)$ treated as described in $A$. The percentage oxidized enzyme flavin obtained within the mixing time was $50 \%, 70 \%$ and $90 \%$ for native enzyme, species 2 and species 3 , respectively.

with oxygen, and the other which catalyzes the hydrogenation and reacts slowly with oxygen.

Reaction of reduced enzyme with MalNEt in the absence of $A B z C O A$. When fully reduced enzyme is mixed anaerobically with MalNEt, $\approx 50 \%$ of the enzyme flavin, corresponding to one half-site of $\mathrm{ABzCoA}-\mathrm{M} / \mathrm{R}$, is reoxidized quickly while the remaining $50 \%$ is reoxidized very slowly $\left(t_{1 / 2}\right.$ on the scale of hours). There is, however, a substantial difference as compared to the reaction with oxygen: the reoxidation of NADH-half reduced enzyme by MalNEt occurs within the mixing time while that with oxygen is slow (Fig. 7, B). This supports the concept of two sites, which differ substantially in their rates of reduction and their reactivity with oxygen and MalNEt respectively. This complementarity of the two sites is supported directly by the results of the experiment shown in Fig. 8. Addition of first MalNEt and subsequently of oxygen to fully reduced enzyme leads to oxidized enzyme in two fast steps.

Reactions of $E \sim F A D_{\text {red }} \sim A B Z C O A$ with oxygen and/or MalNEt. The $\mathrm{O}_{2}$ reaction of the fully reduced $\mathrm{ABzCoA}-\mathrm{M} / \mathrm{R}$ $\sim \mathrm{ABzCoA}$ complex leads to formation of product(s) as represented by Eqn (3) or Scheme 1 and involves quite a complicated sequence of steps as will be detailed in the following paper (Langkau and Ghisla, 1995). Addition of MalNEt to ABzCoA$\mathrm{M} / \mathrm{R}_{\mathrm{red}} \sim \mathrm{ABzCoA}$ leads to rapid (re)oxidation of $\approx 50 \%$ of the enzyme flavin, and subsequent addition of $\mathrm{O}_{2}$ to rapid formation of fully oxidized $\mathrm{ABzCOA}-\mathrm{M} / \mathrm{R}$. This is qualitatively what is observed in the absence of $\mathrm{ABzCoA}$ (compare Fig. 8), the difference being the formation of aromatic product (Scheme 1, III). The sequence is represented by Eqn (4). In contrast to this, when the substrate complex of half-reduced enzyme $\left(E \sim F A D_{\text {redr2 }}\right.$ $\sim \mathrm{ABzCoA}$ ) is reacted with $\mathrm{O}_{2}$ only slow reoxidation ensues and substrate does not react according to $\mathrm{Eqn}(5)\left(\mathrm{E} \sim \mathrm{FAD}_{\mathrm{red} / 2}\right.$ $\sim \mathrm{ABzC} O \mathrm{~A}$ was obtained by titration with NADH up to the half- 


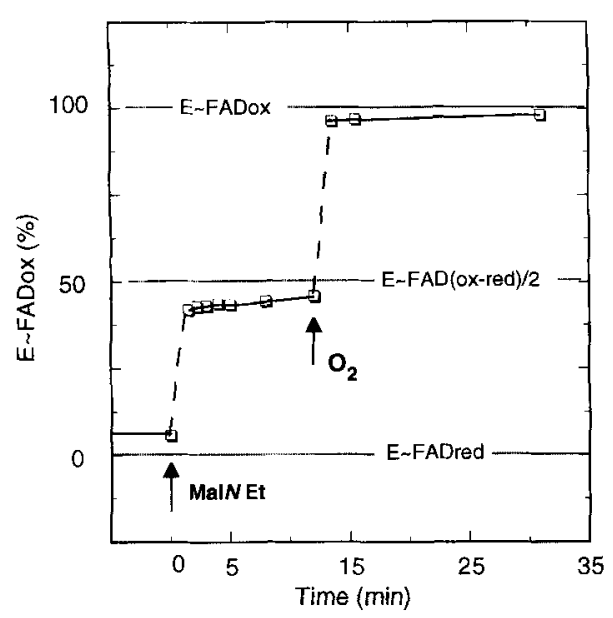

Fig. 8. Reoxidation of NADH-reduced ABzCoA-M/R by MalNEt and oxygen. Reduction conditions were as described in Fig. 6 (A) and at $\approx 45 \mathrm{~min} 95 \%$ reduction was achieved. $20 \mu \mathrm{l}$ MalNEt (final concentration $2 \mathrm{mM}$ ) were then added from a second side arm and this caused $\approx 40 \%$ reoxidation within the time of mixing $(\approx 1 \mathrm{~min})$ as monitored from the absorbance increases at $454 \mathrm{~nm}$, followed by minor spectral changes within the next $12 \mathrm{~min} . \mathrm{O}_{2}$ was then admitted yielding $>95 \%$ reoxidized enzyme in less than $1.5 \mathrm{~min}$.

reduced state and subsequent addition of $\mathrm{ABz} C \mathrm{~A}$ ). This result corresponds to that which is observed in the absence of $\mathrm{ABzCoA}$ as shown in Fig. 7. In these experiments formation of products III and IV (Scheme 1) can be deduced by their absorption in the near-ultraviolet (Langkau et al., 1990) and perturbation of the spectrum of oxidized $\mathrm{ABzCOA}-\mathrm{M} / \mathrm{R}$.

These results are again consistent with the occurrence of two different flavin sites, which do not exchange redox equivalents on the time scale relevant for catalysis. Furthermore they show that in the course of formation of IV monooxygenation precedes hydrogenation.

$$
\begin{gathered}
\mathrm{E} \sim \mathrm{FAD}_{\text {red }} \sim \mathrm{ABzCoA} \underset{\text { fast }}{\frac{\mathrm{O}_{2}}{\text { fast }}} \mathrm{E} \sim \mathrm{FAD}_{\mathrm{ox}}+\text { products }(\text { III, IV }) \\
\mathrm{E} \sim \mathrm{FAD}_{\mathrm{red}} \sim \mathrm{ABzCoA} \stackrel{\text { MalNEt }}{\text { fast }}\left[\mathrm{E} \sim \mathrm{FAD}_{\text {red/2 }} \sim \mathrm{ABzCoA}\right] \\
\frac{\mathrm{O}_{2}}{\text { rast }} \mathrm{E} \sim \mathrm{FAD}_{\mathrm{ox}}+\mathrm{ABz}(\mathrm{OH}) \mathrm{CoA}(\mathrm{III})
\end{gathered}
$$

$$
\left[\mathrm{E} \sim \mathrm{FAD}_{\mathrm{red} / 2} \sim \mathrm{ABzCoA}\right] \frac{\mathrm{o}_{2}}{\text { slow }} \mathrm{E} \sim \mathrm{FAD}_{\mathrm{ox}}+\mathrm{ABzCoA}(\mathbf{I}) .
$$

Steady-state analysis of the reaction with MalNEt. The enzyme-catalyzed oxidation of NADH with MalNEt serving as an artificial electron acceptor was investigated by initial rate measurements. Since the oxidase activity of the enzyme is considerably lower compared to turnover with MalNEt the experiments could be performed under aerobic conditions and analyzed as a classical two-substrate enzyme-catalyzed reaction. Consideration has to be given to the fact that MalNEt is also an inhibitor of $\mathrm{ABzCoA}-\mathrm{M} / \mathrm{R}$ in addition to its capacity as an electron acceptor. This causes initial rates to become slower with increasing incubation time. The steady-state equation for an enzyme-catalyzed reaction involving two substrates (NADH and MalNEt) is

$e / v=\phi_{0}+\frac{\phi_{\mathrm{NADH}}}{[\mathrm{NADH}]}+\frac{\phi_{\text {MalNEt }}}{[\mathrm{MalNEt}]}+\frac{\phi_{\text {MalNEt } \mathrm{NADH}}}{[\mathrm{MalNEt}][\mathrm{NADH}]}$

in which $e$ is the concentration of active centers and $v$ is the observed initial rate. A set of virtually parallel lines was obtained in a Lineweaver-Burk plot of initial velocities versus the concentration of NADH at various levels of MalNEt (data not shown). A secondary plot of the $y$-axis intercepts versus reciprocal MalNEt concentration also yielded a straight line indicating that the last term in Eqn $(6)$ approaches zero $\left(\phi_{\text {MalNEt, NADH }} \approx 0\right)$, and are consistent with the occurrence of a 'ping-pong' or enzyme-substitution mechanism. The kinetic constants obtained from the various plots are: $V_{\max }=6550 \mathrm{~min}^{-1}\left(1 / \phi_{0}\right)$, $K_{\mathrm{m}(\mathrm{NADH})}=26 \mu \mathrm{M}\left(\phi_{\mathrm{NADH}} / \phi_{0}\right)$ and $K_{\mathrm{m}(\mathrm{MalNE})}=0.47 \mathrm{mM}$ ( $\phi_{\text {MalNE }} / \phi_{0}$; for conditions see Materials and Methods).

\section{DISCUSSION}

The puzzling observation of Buder and Fuchs (1989) that $A B z C o A-M / R$ can separate into three active fractions upon chromatography on Mono $\mathrm{Q}$ can now be partially rationalized. Our results are compatible with the interpretation of these authors, that there must be at least two ionically different species of ABzCoA-M/R-monomers $\alpha$ and $\alpha^{\prime}$ which can form the dimer species $\alpha \alpha, \alpha \alpha^{\prime}$ and $\alpha^{\prime} \alpha^{\prime}$. Additionally, the finding of two minor peaks 1a and 2a (see Fig. 3) suggests the existence of further species. The molecular differences between $\alpha$ and $\alpha^{\prime}$ have not yet been identified. However, it is clear that the microheterogeneity does not result from oxidation of SH-groups, as was described e.g. for $p$-hydroxybenzoate hydroxylase (Van Berkel and Müller, 1987) since incubation of $\mathrm{ABzCoA}-\mathrm{M} / \mathrm{R}$ with $\mathrm{H}_{2} \mathrm{O}_{2}$ does not result in a change of the peak ratios upon chromatography on Mono $\mathrm{Q}$ ion-exchange resin. Furthermore there is no correlation of the microheterogeneity with the different activities of the two active sites. The five species show closely similar activities with $\mathrm{ABzCOA}$ as well as with MalNEt upon reconstitution to full FAD content. The differences of species $\alpha$ and $\alpha^{\prime}$ are thus caused by ionic heterogeneity of the protein and this, in turn, appears to affect directly or indirectly binding of FAD.

The different site reactivities observed with $\mathrm{ABzCOA}-\mathrm{M} / \mathrm{R}$ in the absence of substrate are consistent with the sequences of Scheme 2 . This includes two active sites $E^{\mathrm{I}}$ and $\mathrm{E}^{\mathrm{II}}$ which differ in their reactivities towards NADH, MalNEt and $\mathrm{O}_{2}$. Fast reduction of oxidized enzyme with NADH in the absence of the aromatic substrate occurs at the site labelled $\mathrm{E}^{\mathrm{II}}$ and yields the halfreduced enzyme species $\left(\mathrm{E}_{\mathrm{ox}}^{\mathrm{I}} / \mathrm{E}_{\mathrm{red}}^{\mathrm{II}}\right)$. $\mathrm{E}^{\mathrm{II}}$ is also the site which reacts readily with MalNEt to reduce it. These two processes result in high activities for the consumption of NADH and MalNEt under steady-state conditions and are represented by the "hydrogenation cycle' $\mathrm{H}^{\mathrm{II}}$. The site $\mathrm{E}^{\mathrm{II}}$, however, reacts only very slowly with oxygen, resulting in a low oxidase activity as represented by cycle $\mathrm{O}^{\mathrm{I}}$.

The companion site $\mathrm{E}^{\mathrm{I}}$ is, in contrast, only slowly reduced by NADH in the absence of $\mathrm{ABzCoA}$, but it is reoxidized readily by oxygen, providing the basis for a second low oxidase activity via cycle $\mathrm{O}^{\boldsymbol{I}}$. Oxidation of $\mathrm{E}_{\mathrm{red}}^{\mathrm{l}}$ is negligible with MalNEt, but very fast with oxygen. In agreement with this, MalNEt reacts rapidly with the $E_{\text {red }}^{\mathrm{II}}$ site of fully reduced enzyme $\left(\mathrm{E}_{\mathrm{red}}^{\mathrm{I}} / \mathrm{E}_{\mathrm{red}}^{\mathrm{I}}\right)$, to produce the half-reduced species $\left(\mathrm{E}_{\mathrm{red}}^{\mathrm{I}} / \mathrm{E}_{\mathrm{ox}}^{\mathrm{II}}\right)$. The latter cannot be obtained directly from $\mathrm{E}_{\mathrm{ox}}^{\mathrm{I}} / \mathrm{E}_{\mathrm{ox}}^{\mathrm{II}}$ by selective reduction of $\mathrm{E}_{\mathrm{ox}}^{\mathrm{I}}$, it is thus substantially different from $\mathrm{E}_{\mathrm{ox}}^{\mathrm{I}} / \mathrm{E}_{\mathrm{rcd}}^{\mathrm{II}}$. As judged from the results of the reoxidation experiments described, there cannot be any appreciable interconversion of the species $\mathrm{E}_{\mathrm{ox}}^{\mathrm{I}} / \mathrm{E}_{\mathrm{red}}^{\mathrm{II}}$ and $\mathrm{E}_{\mathrm{red}}^{\mathrm{I}} / \mathrm{E}_{\mathrm{ox}}^{\mathrm{II}}$. This suggests that a (kinetic) barrier prevents exchange of redox equivalents between the two cofactors. The latter could be located at sufficient distance from each other, or might not have a favorable reciprocal orientation.

Since $\mathrm{O}_{2}$ reacts efficiently only at the $\mathrm{E}_{\mathrm{red}}^{\mathrm{I}}$ but not at the $\mathrm{E}_{\mathrm{red}}^{\mathrm{I}}$ site, the sequence represented by the dashed lines in Scheme 2 is viable for oxygen consumption only in the presence of MalNEt, which oxidizes $E_{\text {red }}^{\mathrm{II}}$ much faster than $\mathrm{E}_{\mathrm{red}}^{\mathrm{I}}$. These different 
Scheme 2. Redox reactions occurring in the absence of $\mathrm{ABzCoA}$ at either $\mathrm{ABzCoA}-\mathrm{M} / \mathrm{R}$ sites $\mathrm{E}^{\mathrm{I}}$ or $\mathrm{E}^{\mathrm{II}}$, using NADH as electron donor and oxygen or MalNEt as acceptors. Site $E^{1}$ is where monooxygenation occurs and site $E^{\mathrm{II}}$ the one which catalyzes hydrogenation and which is reduced first by NADH. Fast steps, the rates of which have been measured in the following paper are denoted by \#.

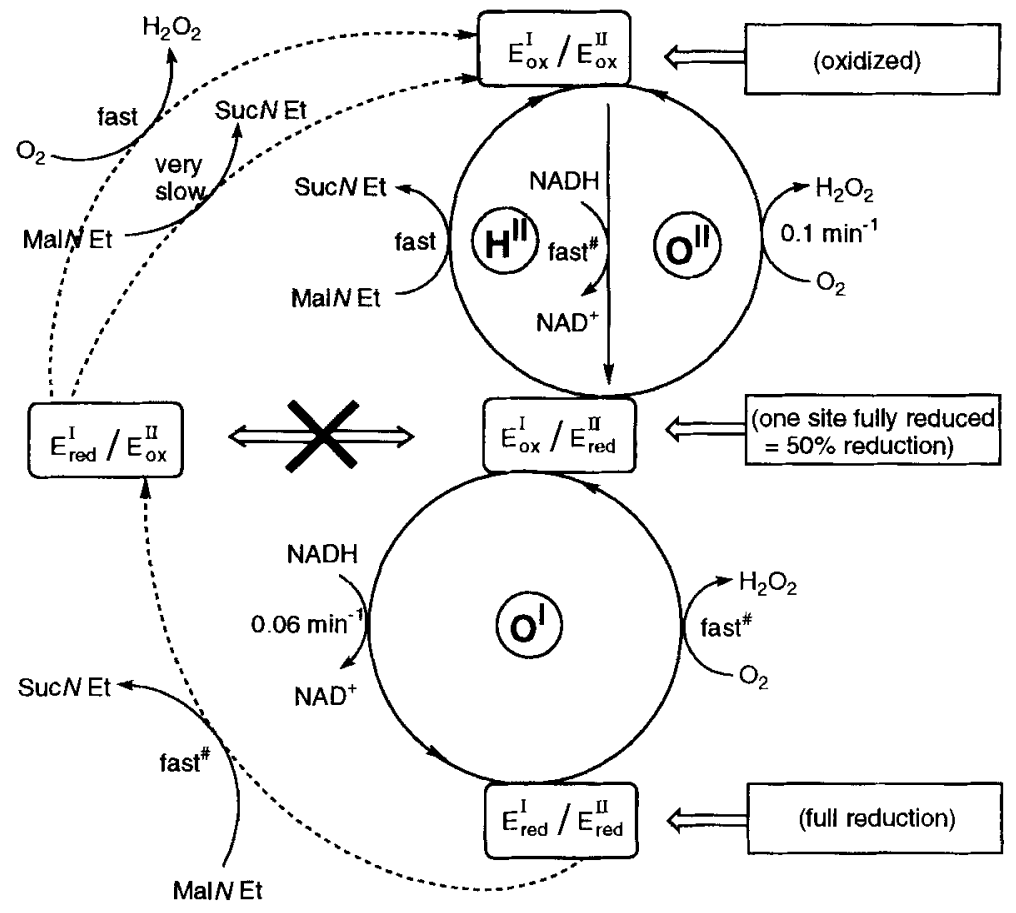

reactivities of sites $\mathrm{E}^{\mathrm{I}}$ and $\mathrm{E}^{\mathrm{II}}$ for oxygen and MalNEt respectively strongly suggest that in catalysis monooxygenation of $\mathrm{ABzCoA}$ occurs at site $\mathrm{E}^{1}$, and is followed by hydrogenation of the non-aromatic intermediate at site $\mathrm{E}^{\mathrm{II}}$ (compare also to Scheme 2 in Langkau et al., 1990). That this is indeed the case is supported by the results from the reoxidation experiments performed in the presence of substrate $\mathrm{ABzCOA}$, and which are represented by Eqns ( 3,4 and 5$)$.

Scheme 2 is also consistent with the reactivities of the three different $\mathrm{ABzCoA}-\mathrm{M} / \mathrm{R}$ species 1, 2, and 3 obtained from chromatography on Mono Q (Fig. 3). Species 1 appears to correspond to fully functional enzyme (containing complete sites $E^{I}$ and $E^{I I}$ ); it thus catalyzes monooxygenation and hydrogenation as shown in Scheme 1. Species 3, which is depleted of $50 \%$ of total FAD and completely of FAD at site $\mathrm{E}^{\mathrm{II}}$, lacks hydrogenation activity. Consequently, during catalysis, the postulated intermediate, $\mathrm{ABzOHCoA}$ * (II) can only rearomatize to $\mathrm{ABzOHCoA}$ (III) either on the enzyme surface or spontaneously (Scheme 1).

Based on the report by Altenschmidt et al. (1992) that $\mathrm{ABzCoA}-\mathrm{M} / \mathrm{R}$ is a homodimer and that it contains 1 molecule $\mathrm{FAD}$ /monomer, the question arises concerning the mode of formation of two active sites both containing a flavin cofactor, and having different catalytic properties. The fact that FAD interacts in different ways with the protein environment at the two sites, as reflected by the major differences in binding/dissociation properties and, most importantly, reactivity, is consistent with the presence of two distinct catalytic sites. The less likely alternative would be two identical sites which become different upon binding of substrate(s), i.e. a strong negative cooperativity effect. Our interpretation is in line with the finding that there is no exchange of redox equivalents between the two flavin cofactors. This suggests a kinetic barrier since the redox potential measurements with $\mathrm{ABzCoA}-\mathrm{M} / \mathrm{R}$ both in the presence and $\mathrm{ab}-$ sence of $\mathrm{ABzCoA}$ do not indicate relevant differences between the two flavins. There are probably also two distinct binding sites for the cosubstrate NADH since in the case of a single one, which would have to access both flavins (compare to location
Scheme 3. Hypothetical schematic arrangement of the two polypeptide subunits of $\mathrm{ABzCOA}-\mathrm{M} / \mathrm{R}$ to form two active sites, and mode of binding of flavin cofactor, and of substrates NADH and ABzCoA. The left and right structures represent the two polypeptide chains which interact to form an asymmetric dimer. Its lower and upper parts form the two different active sites $\mathrm{E}^{\mathrm{I}}$ (hydroxylation) and $\mathrm{E}^{\mathrm{II}}$ (hydrogenation). An enzyme in which the two chains fold in two distinct patterns yielding two active centers $E^{x}$ and $E^{11}$ each and forming a single binding pocket for $\mathrm{ABzCoA}$ is also conceivable, albeit less attractive.

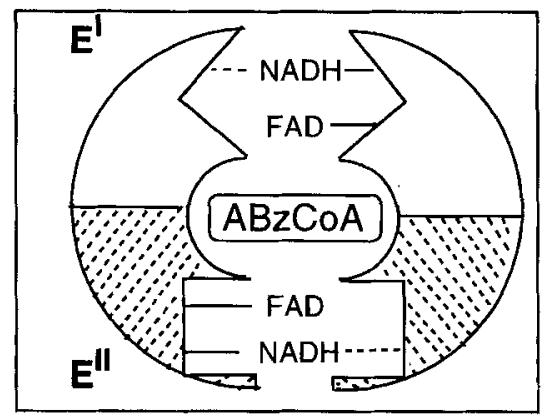

of $\mathrm{ABzCoA}$ in Scheme 3), one might expect exchange of redox equivalents between the latter. We envisage Scheme 3 as a possible model for rationalizing our findings. In this scheme there is only one binding site for the substrate $\mathrm{ABzCoA}$ which must be able to access both sites $\mathrm{E}^{\mathrm{I}}$ and $\mathrm{E}^{\mathrm{II}}$. Clearly the question about the factors which induce creation of two different active sites using two seemingly identical polypeptide chains is of basic importance. While there are plenty of examples of enzymes in which two or more different cofactors act or participate in acting on a single substrate, a notable one being the Molybdo-FeSFAD oxidases such as xanthine oxidase, the finding of the same cofactor being used in a single protein for the catalysis of two different chemical reactions is unprecedented to our knowledge. An analogy could be represented by the FAD and FMN cofactors in NADPH- $P_{450}$ reductases (Vermillion and Coon, 1978) or 
in dihydroorotate dehydrogenase (Friedmann and Vennesland, 1960; Miller and Massey, 1965), but in these two latter cases one center is assumed to serve in simply electron transfer.

The observation of three enzyme forms separating on ionexchange chromatography does not exclude the hypothesis that post-translational modifications play a role in the sense that they might be involved in the differentiation of the active sites. The fact that dimer species $\alpha \alpha, \alpha \alpha^{\prime}$, and $\alpha^{\prime} \alpha^{\prime}$ all have approximately the same amount of hydrogenation and monooxygenation activities, however, implies that this could not be the only cause. The point should also be stressed that the occurrence of the heteromeric species having different affinities for FAD has probably nothing to do with the existence of a dimer with two different active centers. On-going experiments aimed at expressing the enzyme in different organisms such as Escherichia coli, and at the determination of the three-dimensional structure might help elucidate this puzzle.

This work was supported by grants from the Deutsche Forschungsgemeinschaft (Gh 2/4-7, Gh 2/6-1) to SG, from the US public Health Service (6M-11106) to VM, and Deutsche Forschungsgemeinschaft (Fu 118/7-2) and Fonds der chemischen Industrie to GF.

\section{REFERENCES}

Altenschmidt, U., Bokranz, M. \& Fuchs, G. (1992) Novel aerobic 2 aminobenzoate metabolism. Nucleotide sequence of the plasmid carrying the gene for the flavoprotein 2-aminobenzoyl-CoA monooxygenase/reductase in a denitrifying Pseudomonas sp., Eur. J. Biochem. $207,715-722$

Brown, K. \& Gibson, D. T. (1984) Anaerobic degradation of 2-aminobenzoate (anthranilic acid) by denitrifying bacteria, Appl. Environ. Microbiol. 48, 102-107.

Buder, R. \& Fuchs, G. (1989) 2-Aminobenzoyl-CoA monooxygenase reductase, a novel type of flavoenzyme. Purification and some properties of the enzyme, Eur. J. Biochem. 185, 629-635

Buder, R., Ziegler, K., Fuchs, G., Langkau, B. \& Ghisla, S. (1989) 2-Aminobenzoyl-CoA monooxygenase/reductase, a novel type of flavoenzyme. Studies on the stoichiometry and the course of the reaction, Eur. J. Biochem. 185, 637-643.

Dixon, M. \& Kleppe, K. (1965) D-amino acid oxidase. I. Dissociation and recombination of the holoenzyme, Biochim. Biophys. Acta 96 , $357-367$.

Egli, R. (1968) Katalysierte Dehalogenierungen mit Natriumborhydrid, Helv. Chim. 51, 2090-2097.

Ellman, G. L. (1959) Tissue sulfhydryl groups, Arch. Biochem. Biophys. $82,70-77$
Friedmann, H. C. \& Vennesland, B. (1960) Crystalline dehydroorotic dehydrogenase, J. Biol. Chem. 235, 1526-1532.

Ghisla, S. \& Massey, V. (1989) Mechanisms of flavoprotein-catalyzed reactions, Eur. J. Biochem. 181, 1-17.

Langkau, B. \& Ghisla, S. (1995) Eur. J. Biochem. 230, 686-697.

Langkau, B., Ghisla, S., Buder, R., Ziegler, K. \& Fuchs, G. (1990) 2 Aminobenzoyl-CoA monooxygenase/reductase, a novel type of flavoenzyme. Identification of the reaction products, Eur. J. Biochem. $191,365-371$.

Lochmeyer, C., Koch, J. \& Fuchs, G. (1992) Anaerobic degradation of 2-aminobenzoic acid (anthranilic acid) via benzoyl-coenzyme $\mathrm{A}$ (CoA) and cyclohex-1-enecarboxyl-CoA in a denitrifying bacterium, J. Bacteriol. 174, 3621-3628.

Miller, R. W. \& Massey, V. (1965) Dehydroorotic dehydrogenase. I. Some properties of the enzyme, J. Biol. Chem. 240, 1453-1465.

Massey, V. \& Hemmerich, P. (1977) A photochemical procedure for reduction of oxidation-reduction proteins employing deazariboflavin as catalyst, J. Biol. Chem. 252, 5612-5614.

Massey, V., Stankovich, M. \& Hemmerich, P. (1978) Light-mediated reduction of flavoproteins with flavins as catalysts, Biochemistry 17 , $1-8$.

Powlowski, J., Dagley, S., Massey, V. \& Ballou, D. P. (1987) Properties of anthranilate hydroxylase (deaminating), a flavoprotein from Trichosporon cutaneum, J. Biol. Chem. 262, 69-74.

Spector, T. \& Massey, V. (1972) p-Hydroxybenzoate hydroxylase from Pseudomonas fluorescens. Reactivity with oxygen, J. Biol. Chem. 247, 7123-7127.

Stöckigt, J. \& Zenk, M. H. (1975) Chemical syntheses and properties of hydroxycinnamoyl-coenzyme A derivatives, $Z$. Naturforsch. $30 \mathrm{c}$, $352-358$.

Van Berkel, W. J. H. \& Müller, F. (1987) The elucidation of the microheterogeneity of highly purified $p$-hydroxybenzoate hydroxylase from Pseudomonas fluorescens by various biochemical techniques, Eur. J. Biochem. 167, 35-46.

Vermillion, J. L. \& Coon, M. J. (1978) Identification of the high and low potential flavins of liver microsomal NADPH-cytochrome $P$ 450 reductase, J. Biol. Chem. 253, 8812-8819.

White-Stevens, R. H. \& Kamin, H. (1970) Uncoupling of oxygen activation from hydroxylation in a bacterial salicylate hydroxylase, Biochem. Biophys. Res. Commun. 38, 882-888.

Yamamoto, S., Katagiri, M., Maeno, H. \& Hayaishi, O. (1965) Salicylate hydroxylase, a monooxygenase requiring flavin adenine dinucleotide. I. Purification and general properties, J. Biol. Chem. 240, $3408-3413$.

Ziegler, K., Braun, K., Böckler, A. \& Fuchs, G. (1987) Studies on the anaerobic degradation of benzoic acid and 2-aminobenzoic acid by a denitrifying Pseudomonas strain, Arch. Microbiol. 149, 62-69. 